$2020,21(1)$, pp. 21 - 38, DOI: 10.18038/estubtda.514731

\title{
SELECTION OF THE MOST APPROPRIATE GROUND MOTION PREDICTION EQUATION FOR LOCAL SEISMIC HAZARD ANALYSIS
}

\author{
Hakan KARACA ${ }^{1, *}$ \\ ${ }^{1}$ Department of Architecture, Niğde Ömer Halisdemir University, Turkey
}

\begin{abstract}
Together with the ever-increasing number of global and local Ground Motion Prediction Equations (GMPEs) and the complexity of the functional forms, incompatibility problems arise in the selection of the most appropriate GMPE for a specific location. Associated with the incompatibility issues, practitioners face a compromise over the precision of prediction because the functional form of the used GMPE that might be developed by considering influential parameters, which might not be available for the considered location. Hence, a modification is required to adjust the considered GMPE to local conditions by using the local ground motion data. The sensitivity of the parameters of the selected GMPEs to the local seismic propagation patterns can be determined only after the adjustment. Together with the attempts to solve the incompatibility and sensitivity problem, the selection of the most appropriate GMPE becomes the selection of the most suitable functional form.

The aim of this study is to select the most appropriate GMPE form for Eskişehir through the guidance of the above statements. A number of GMPEs are selected according to the criteria of wider utilization and recognition. All the candidate GMPEs were subjected to adjustments, including some minor modifications and the calibration of the coefficients by using the indigenous data. Then, a number of statistical and visual procedures were applied including the performance test of the adjusted GMPEs with the records of the two largest earthquakes that occurred in the region. The study highlights the influence of the local seismic behavior on the performance of various functional forms of the candidate GMPEs.
\end{abstract}

Keywords: Eskişehir, Ground Motion Prediction Equation, LLH method, EDR method, Residual Analysis

\section{INTRODUCTION}

The large variance of the performances of various GMPEs motivated the development of a selection scheme to find out the most appropriate one for a local seismic hazard analysis. Obviously, the variation in the spectral acceleration values of GMPEs at the same magnitude and distance indicates the level of dependency of the performances of GMPEs on their functional forms and the databases used in their development. The fact that the functional forms of GMPEs are already suited to model the propagation patterns of the records in the database used in their development, there is also an intertwined relationship with the functional form and the characteristics of the database.

Many studies were conducted to investigate the applicability issues of GMPEs to any specific location considering the local ground motion database, geological settings and site conditions $[1,2,3,4,5,6,7$, $8,9,10,11]$. Particularly, the equations of NGA-WEST2 and their predecessors were repeatedly experimented with the European dataset, which generally lacks a substantial number of ground motion parameters compared to the NGA-WEST2 dataset $[5,7,10,12]$.

In all these studies, the performance of the selected GMPEs was evaluated using the original coefficients. However, it should be noted that if a GMPE is developed not only by using the indigenous strong ground motion data but also by including the data from different seismic sources or by using ergodic assumptions the local pattern of propagation cannot be identified.

In the selection of the most suitable GMPE for a specific location, a reliable comparison of GMPEs is required, including the examination of the strong motion databases used in their development. However,

*Corresponding Author: karaca26@hotmail.com

Received: 18.01. 2019 Published: 31.03.2020 
it should also be noted that considering the level of complexities of the databases, a comparative study is not an easy task in terms of the identification of local seismic propagation patterns. To give an example, regarding the level of detail of records in the NGA databases [12], one might reach a conclusion that it would be a stretch to try to adopt the equations elsewhere.

When the databases are compiled by using indigenous data, the comparison of the databases might yield specific conclusions about the seismic propagation characteristics of a specific region. However, if that is not the case, a database comparison could only help to differentiate the main trends of the strong motion propagation of the records and the expressions to be included in the functional form to model these trends. From another point of view, it can be said that database comparison might not be required since the developers of the GMPEs have prescribed different application limitations for the use of the equations for different magnitudes, site conditions, fault styles and distance ranges. Therefore, depending on the database used and the functional forms, there is a possibility of over-estimating or under-estimatingthe local seismic effects. If earthquakes with different magnitude distributions from the local distribution dominate the database, the magnitude scaling, log-distance scaling and magnitude saturation parameters could cause a bias in the modeling of the local behavior. Moreover, the utilization of a different distance parameter whether the closest horizontal distance or hypocentral distance in the development phase of a GMPE might cause a variation in the calculated spectral values at the same distance [13].

As the variance in the performances of various GMPEs largely influences the estimation of the seismic hazard, researchers suggested one of the classical approaches, a logic tree method, to reduce the model bias by averaging the median values of the selected GMPEs and by modeling uncertainty. However, the considerable variation in GMPEs regarding their performances and varying sigma values not only makes the selection of a single equation difficult, but renders the selection of a number of equations problematic as well.

Considering the aforementioned facts about the performances of various GMPEs, goodness-of-fit tests and a residual analysis are required to handle the problem of selecting the best-suited form of GMPE for a specific location. In the mentioned analysis and tests, the predicted spectral values are calculated by the coefficients of the equations, which are derived by using the databases of the developers. Thus, the probability of obtaining highly varied spectral values cannot be avoided. Therefore, in order to overcome the parameter compatibility issues with the local database and local propagation characteristics, the adjustment of the GMPEs with the local database is necessary. The adjustment of the GMPEs with the local database not only solves the problem of parameter compatibility but also the conformance of the functional form with the local database.

It should also be noted that the generation of a local GMPE with the local database seems to be the best solution to the problem. However, the assessment of various forms of equations with the local database has several benefits compared to the development of an equation.

Considering the above-mentioned aspects regarding the selection of a suitable GMPE for a local seismic hazard analysis, this study tries to optimize the selection of a suitable GMPE for a specific location with noticeably limited amount of data. Together with the limited local database available compared to the commonly utilized GMPEs developed by using NGA, RESOURCE and specifically compiled large databases, the candidate GMPEs are adapted and adjusted to the local database as well. The adjustments made through the exclusion of some complex parameters due to the lack of local data generate a new set of GMPEs which are not very different from the original forms. However, for the sake of presenting a reasonably optimal solution to the GMPE selection problem, the functional forms of the candidate GMPEs with the adjusted parameters were evaluated with respect to their performances in the representation and modeling of the local data. The comparison of the performance of the selected 
GMPEs with the original coefficients and the performance of the adjusted functional forms was not performed as the adjustments and the new set of coefficients, which are derived by using the local database, make the comparison inappropriate. Indeed, as this study aims to offer a reasonable way of selection of best functional form for a local seismic hazard analysis, the comparison of the performances of GMPEs with the original functional forms and coefficients is not necessary. The advantages and the shortcomings of the presented method are further discussed in the conclusion section. Shortly, the main contribution of this study, is to lay out a robust technique of evaluating the GMPEs for their appropriateness for local seismic hazard analysis. In contrast to the widely accepted approaches, which primarily focus on the reduction of the uncertainties even at a cost of not accounting for the non-ergodic and time-variant characteristics of the data, the proposed approach is based on evaluation of the GMPEs with newly developed techniques in a robust manner. The strength and weaknesses of the approach is elaborated throughout the study.

\section{MATERIALS}

A local strong ground motion database was compiled by considering the earthquakes which occurred within the area encircled by a $300 \mathrm{~km}$ radius circle centered at Eskişehir. Then, a list of candidate GMPEs were determined from amongst the NGA-WEST2 equations, European equations and local GMPEs developed by using the local Turkish data.

\subsection{The Local Strong Ground Motion Database}

In order to evaluate the selected GMPEs with respect to the local data, past seismic activity of the considered area is investigated. Although certain constraints of the equations may be weakened due to the limitations and biases of the local data, the intrusion of records from any other site was not allowed. The aim of this restriction was to capture the region specific behavior of the propagation. Moreover, assuming that the database has enough number of records to identify the local propagation patterns, the aleatory variability inherent in the scaling of the spectral acceleration values with respect to magnitude, distance and other parameters would be specific to the location of interest.

The catalog compiled by General Directorate of Disaster Affairs (GDDA) (Currently Disaster and Emergency Management Presidency, DEMP) [14] was examined to gather the necessary earthquake activity data. The catalog was subjected to elimination by using engineering judgment to include only the strong motion events with the damage inflicting capability on a nearby settlement. The database is composed of 198 records from 27 earthquakes that occurred between 1976 and 2019. The priority was to compile a homogeneous earthquake database to reduce the bias.
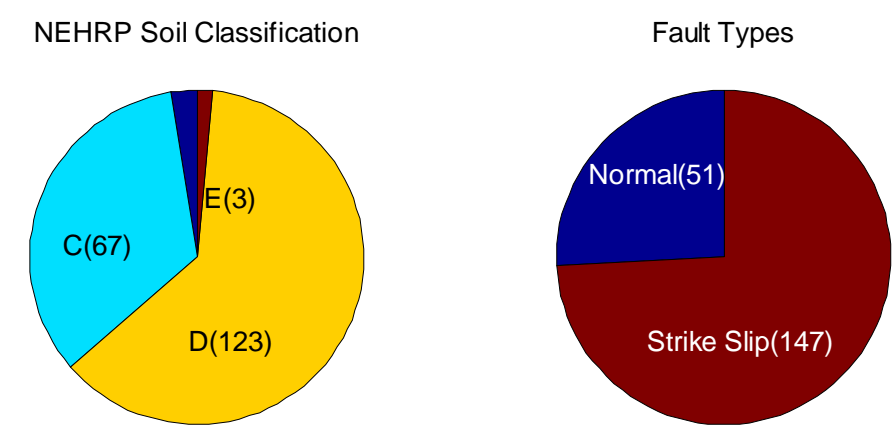

Figure 1. Site Classification and Fault Type Distribution

Among several distance measures, the closest horizontal distance to the rupture surface, which is called theJoyner-Boore distance, was utilized in the evaluation of the database. İzmit (1999) and Düzce (1999) 
earthquakes, which are the two earthquakes with a moment magnitude greater than 7.0, caused a large surface rupture. The distances for these two earthquakes were assigned as the closest horizontal distance from the surface projection of the rupture to the recording station. The shear wave velocities at the recording sites were gathered from [14]. Most of the recording station sites are classified as either $\mathrm{C}$ or $\mathrm{D}$, which is also a general situation considering all the recording station sites in Turkey. The fault types reflect the local geophysical pattern of the region, which is dominated by the strike-slip faults on the north and normal faults in the south of Eskişehir.
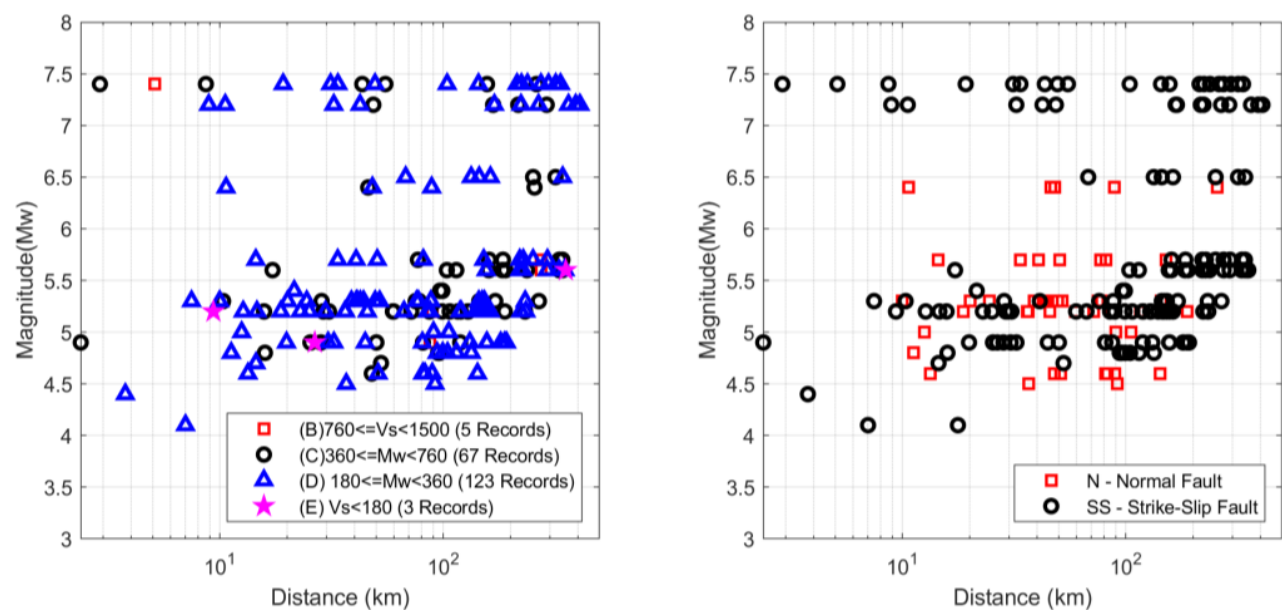

Figure 2. Distribution of Magnitude and Distance of the Earthquakes in the Local Database

As seen in Figure 2, the recording distance varies from $2.4 \mathrm{~km}$ to $409 \mathrm{~km}$, and the data is distributed in a uniform pattern in terms of recording distance. The geometric means of the two horizontal components were used as input acceleration. All the records were processed by using a 4-pole Butterworth filter by varying low cutoff and high cutoff frequencies and through the baseline correction method. As shown in Figure 3, the epicenter of the earthquakes in the database and the recording stations were chosen in such a way that the traveling paths remain within the area surrounding Eskişehir.

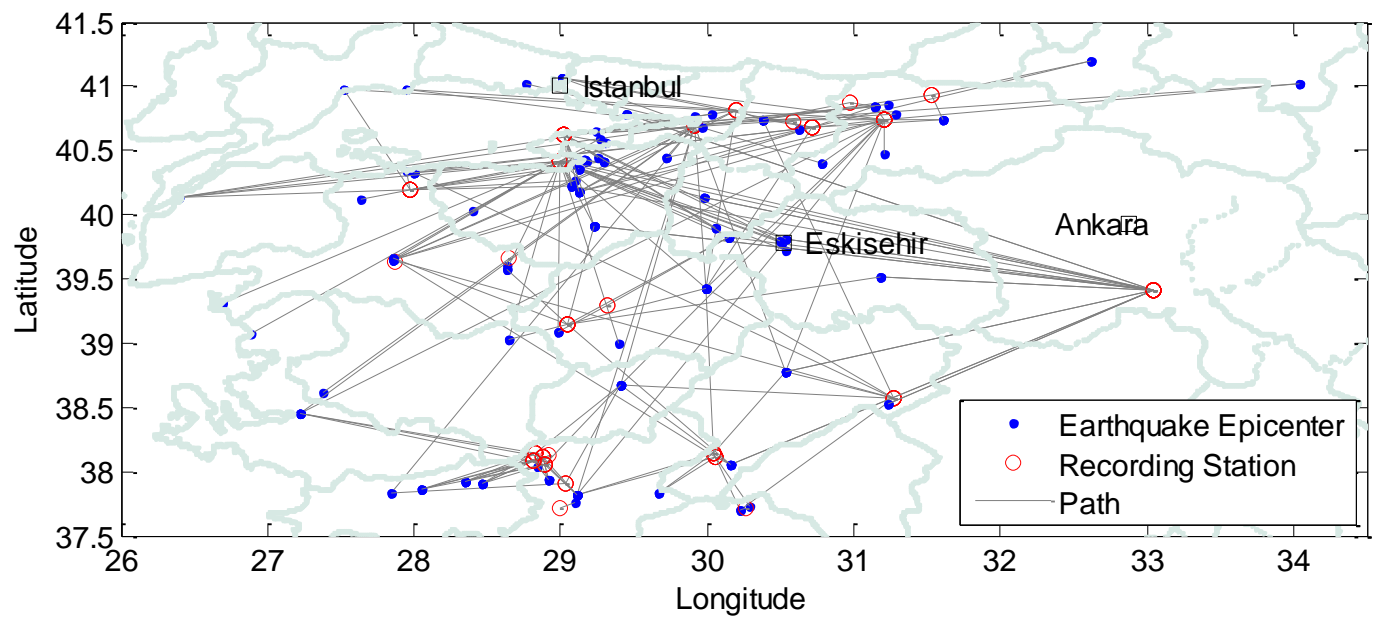

Figure 3. The Epicenters of Earthquakes and the Locations of the Recording Stations 


\subsection{Candidate GMPEs}

As the most important issue in the development of the GMPEs, the identification of the locality of the seismic event propagation totally depends on the completeness of the database in terms of magnitude, distance and other parameters. As the databases of NGA-WEST2 [12] project, the RESOURCE [15], and the recently compiled Turkish strong motion database [16]possess a very wide coverage in terms of parameters, the equations based on these databases were given priority in the selection of candidate GMPEs. The originality of the models are also evaluated in the selection, such that only the GMPEs with significantly unique parameters are considered. Hence a newly developed model with the same parameters and relationships are not considered.

As a result, the equations of NGA-WEST2 Abraham, Silva and Kamai, 2014 [17] (ASK14); Boore, Atkinson, Seyhan and Stewart, 2014 [18] (BSSA14); Campbell and Bozorgnia, 2014 [19] (CB14); Chiou and Youngs, 2014 [20] (CY14) and Idriss, 2014 [21] (I14)); the European equations of Ambraseys et al.,2005 [22] (AM05) and Akkar and Bommer, 2010 [23] (AB10); and the Turkish equations of Kagan and Gulkan, 2014 [24] (KG04) and Akkar and Cagnan, 2010 [25] (AC10) were considered.

As the oldest GMPEs of the list of candidates, in the development of KG04 and AC10, only the earthquake records from Turkish ground motion database were used. The databases used in the development of these two local equations have similar distribution characteristics with the database used in this study in terms of higher magnitude earthquakes.

Two Pan-European GMPEs of [22] and [23] were also considered for this study. The reason behind the selection of the two models (AM05, AB10) from amongst several European equations is that the selected equations are designed for Pan-European data and distinct functional forms that are worth consideration. The equation $\mathrm{AB} 10$, was proposed to reduce the dependency of the sigma values on magnitude. In addition, the magnitude dependency of the sigma values and the fluctuation with respect to the spectral period is largely reduced in their new equation. The GMPE was developed as the Pan-European equation including the data from Europe, Mediterranean and the active regions of Middle East. It should be noted that since the model proposed by [26], which was indeed developed as a Pan-European model, is based on AC10, the functional form is not included as a separate model.

The NGA-WEST2 project compiled a large database of earthquakes with magnitudes ranging from 3.0 to 7.9. Among the five sets of NGA-WEST2 equations, the GMPEs of ASK14, BSSA14, CB14, I14 and CY14 were developed to supersede the equations of NGA-WEST1 and NGA projects. Though the database used in developing these equations is the same, the functional forms and the records included in the development of the equations are quite different. Except for BSSA14, the distance scaling of the ground motion is modelled by the rupture distance in all the models. In addition, the magnitude scaling of the ground motions is expressed by setting different magnitude intervals, and for each magnitude interval, linear or quadratic models were developed. Except for I14, all the NGA-WEST2 equations are very complex due to the existence of a number of split magnitude values and expressions for different ranges of magnitudes for several parameters, which makes the equations very much dependent on the distribution of these parameters in the database. The introduction of the parameters of hanging wall, depth to top rupture, large distance, soil depth, the rake angle, dip of the rupture plane, depth to the 2.5 $\mathrm{km} / \mathrm{s}$ shear wave velocity and basin depth complicates the equations. In addition to complexity, the applicability of the equations for other locations is questionable due to the incompatibility issues between the parameters and the local database. Since most databases lack most of these values, before the utilization of these equations, necessary adjustments have to be performed. In this study, the nonlinear site parameters of ASK14, BSSA14 and CB14 were not included due to the lack of data in the established database. Thus, among the NGA-WEST2 equations, all the equations except for [20] (CY14) 
are selected as candidate GMPEs. CY14 was eliminated due to the number of parameters, the complexity of the functional form and the limited size of the gathered database.

\section{METHOD}

Figure 4 summarizes the applied evaluation procedure for the selection of the most appropriate GMPE for local seismic hazard analysis. Initially, the selected GMPEs were subjected to a pre-evaluation scheme as proposed by [27]. The purpose of development, the forms of equations, input parameters and the application criteria of these equations were examined. Then, in order to overcome the locality issues and the compatibility of the parameters of a selected GMPE with the local dataset, the selected GMPEs were adopted through adjustments and calibrations [11]. Although the adjusted GMPEs might result a deviation from the original performance, it would still serve the purpose of the study since the study aims to adopt the GMPEs. The necessary minor modifications due to local conditions were incorporated into the functional forms of GMPEs. If the local data related to a parameter is not adequate, or if the parameter is irrelevant, that parameter was omitted from the equation. After the necessary adjustments of the parameters, the coefficients of the remaining parameters of GMPEs were calibrated by using a simple multiple regression analysis program developed in MATLAB. Single stage multiple regression analysis was performed for the derivation of the coefficients. The observed ground motion values and the parameters of the ground motions in the database were regressed simultaneously.

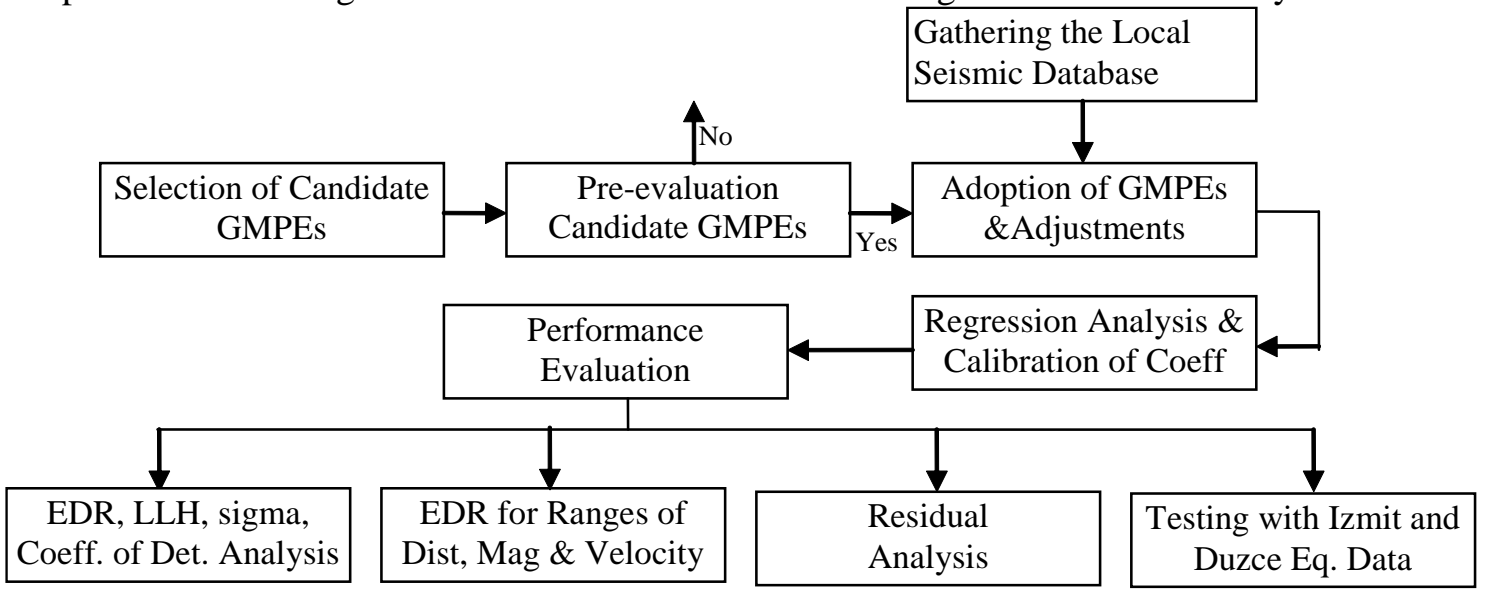

Figure 4. Summary of Evaluation Procedure

In order to test the goodness-of-fit of the observed and computed spectral acceleration values, among the several available statistical methods, the methods proposed by [28] and [29] were used. The sigma values of the adjusted GMPEs were also included in the statistical analysis. These values were sought for a range of magnitude and distance ranges in order to identify the performance of GMPEs with respect to the distance and magnitude scaling characteristics of the records in the database.

The shortcomings of the Log-Likelihood (LLH) method of [26] and the Euclidean Distance Based Ranking (EDR) method of [29] in the determination of the statistical quantities with respect to the magnitude, distance and other variables were compensated by classical residual analysis. The performance of the adjusted GMPEs are also tested with İzmit and Düzce Earthquakes. Then, the performances of the adjusted GMPEs with their calibrated coefficients were evaluated for the final selection. 


\subsection{The Evaluation of Candidate GMPEs}

As it was laid out clearly in [27], the purpose of development, the functional forms, input parameters and the application limits must be examined. In addition to the mentioned criteria, as specific to this study, considering the number of the records in the gathered database, the number of parameters, the level of complexity and magnitude and other parametric intervals becomes important before deciding to consider a GMPE for its functional form. Firstly, it should be mentioned that all the GMPEs involve parameters to express magnitude scaling, higher magnitude saturation, and magnitude dependent distance scaling of the ground motions. While magnitude scaling is expressed with only quadratic magnitude terms in some equations, other equations express it with the introduction of the magnitude intervals.

Each equation has different parameters depending on the purpose of use, while most equations include the basic variables of magnitude, distance, fault types and site classification parameters. Some equations require very specific information about the local site conditions such as sediment depth, fault mechanisms and detailed geological properties of the earthquakes such as hanging wall and the depth to rupture parameters. Table 1 summarizes and compares the parameters used in the selected equations. As shown in the table, the magnitude terms are agreeably in moment magnitude, and in some equations, magnitudes are ranged into two or three groups.

Table 1.Comparison of GMPEs According to Input Parameters

\begin{tabular}{|c|c|c|c|c|}
\hline GMPE & Magnitude & Distance & $\begin{array}{c}\text { Fault } \\
\text { Mechanism* }\end{array}$ & Site Classification \\
\hline KG04 & $\mathrm{M}_{\mathrm{w}}$ & $\mathrm{RJB}_{\mathrm{JB}}$ & $-* *$ & $\mathrm{~V}_{\mathrm{s} 30}$ \\
\hline AM05 & $\mathrm{M}_{\mathrm{w}}$ & $\mathrm{R}_{\mathrm{JB}}$ & $\mathrm{T}, \mathrm{N}, \mathrm{O}$ & Based on $V_{\mathrm{s} 30}$ classification \\
\hline $\mathrm{AB} 10$ & $\mathrm{M}_{\mathrm{w}}$ & $\mathrm{RJB}_{\mathrm{JB}}$ & $\mathrm{R}$ and $\mathrm{N}$ & Based on $V_{\mathrm{s} 30}$ classification \\
\hline $\mathrm{AC} 10$ & $\begin{array}{l}\mathrm{M}_{\mathrm{w}} \leq 6.50 \\
\mathrm{M}_{\mathrm{w}}>6.50\end{array}$ & $\mathrm{R}_{\mathrm{JB}}$ & $\mathrm{R}, \mathrm{N}$ and others & $\begin{array}{c}\mathrm{V}_{\mathrm{s} 30} \text {, and for nonlinear parameter expected } \\
\text { PGA at } V_{\mathrm{s} 30}=760 \mathrm{~m} / \mathrm{s} \text { is used }\end{array}$ \\
\hline ASK14 & $\begin{array}{l}\mathrm{M}_{\mathrm{w}}>\mathrm{c}_{1} \\
\mathrm{M}_{\mathrm{w}}<\mathrm{c}_{1} \\
\end{array}$ & $\begin{array}{c}\mathrm{R}_{\mathrm{rup}}, \mathrm{R}_{\mathrm{JB}}, \\
\mathrm{R}_{\mathrm{x}} \\
\end{array}$ & $\mathrm{R}, \mathrm{N}$, others & $\begin{array}{l}\mathrm{V}_{\mathrm{s} 30} \text {, and for nonlinear parameter expected } \\
\text { PGA at } V_{\mathrm{s} 30}=1100 \mathrm{~m} / \mathrm{s} \text { is used }\end{array}$ \\
\hline BSSA14 & $\begin{array}{l}\mathrm{M}_{\mathrm{w}}<\mathrm{M}_{\mathrm{h}} \\
\mathrm{M}_{\mathrm{w}}>\mathrm{M}_{\mathrm{h}}\end{array}$ & $\mathrm{R}_{\mathrm{JB}}$ & $\begin{array}{l}\mathrm{R}, \mathrm{N}, \mathrm{SS} \text { and } \\
\text { others }\end{array}$ & $\begin{array}{l}\mathrm{V}_{\mathrm{s} 30} \text {, and for nonlinear parameter expected } \\
\text { PGA at } V_{\mathrm{s} 30}=760 \mathrm{~m} / \mathrm{s} \text { is used }\end{array}$ \\
\hline CB14 & $\begin{array}{c}\mathrm{M}_{\mathrm{w}}<5.5 \\
5.5<\mathrm{M}_{\mathrm{w}} \leq 6.5 \\
6.5<\mathrm{M}_{\mathrm{w}} \\
\end{array}$ & $\mathrm{R}_{\text {rup }}, \mathrm{R}_{\mathrm{JB}}$ & $\mathrm{R}, \mathrm{N}$ and others & $\begin{array}{l}\mathrm{V}_{\mathrm{s} 30} \text {, and for nonlinear parameter expected } \\
\text { PGA at } V_{\mathrm{s} 30}=1100 \mathrm{~m} / \mathrm{s} \text { is used }\end{array}$ \\
\hline I14 & $\begin{array}{l}M_{w} \leq 6.75 \\
M_{w}>6.75\end{array}$ & $\mathrm{R}_{\text {rup }}$ & SS, R and others & $\mathrm{V}_{\mathrm{s} 30}$ \\
\hline
\end{tabular}

*T: Thrust fault, N: Normal fault, SS: Strike-slip fault, R: Reverse fault, R/O: Reverse oblique fault ** No parameter is defined

In all the GMPEs, the magnitude dependent distance scaling of the ground motions is expressed by a parameter containing the magnitude as multiplier. The choice of the right distance parameter largely influences the performance of the proposed model of GMPE. As can be seen in Table 1, the JoynerBoore distance and rupture distance terms dominate the equations. If the relative influence of these two distinct distance terms is compared by using hypothetical values, the significant difference between the performances could be revealed as displayed in Figure 5 [13].

As shown in the third column of Table 1, the primary distance measure is the Joyner-Boore distance, which is the closest horizontal distance from the recording site to the surface projection of the rupture plane. It is used in $\mathrm{KG} 04, \mathrm{AM} 05, \mathrm{AB} 10, \mathrm{AC} 10$ and BSSA14 as the main term of the distance parameter and in hanging wall parameters in CB14 and ASK14. The second common distance measure is the rupture 
distance, which is defined as the closest distance from the site to the rupture plane. Except for KG04, all the GMPEs consist of a fault parameter, which takes unity values depending on the existence of the considered fault type. KG04 excludes the fault parameter due the lack of pattern of dependence of the ground motion amplitudes on the fault styles in the gathered database.
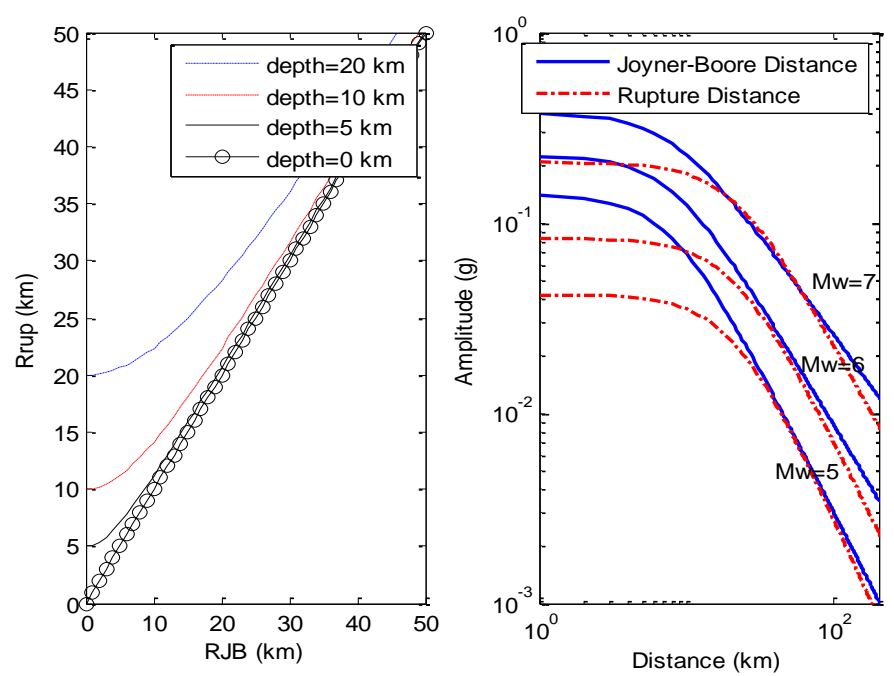

Figure 5. Variation of the Rupture Distance and Joyner-Boore Distance for Point Source and the Resulting Influence on the GMPE Performance

The site classification criteria vary greatly among the equations; however, the top $30 \mathrm{~m}$ shear wave velocity is used as thesite parameter in most of them. Nonlinearity of the site response is considered in AC10, ASK14, BSSA14 and CB14. In this study, for the sake of coherence and the locality issues of nonlinearity, the modeling of site effects was performed by including linear site response terms only. The additional site effects such as sediment thickness, model basin effect and depth to the $1000 \mathrm{~m} / \mathrm{s}$ velocity and depth to the $2500 \mathrm{~m} / \mathrm{s}$ shear wave velocity, which are introduced in some models, were not considered due to the lack of data in the gathered database.

Each developer compiled and used a different catalog of earthquakes in the development of their equations; therefore, they prescribed different applicability limits. These limits are very important in the evaluation of the functional forms because not only the coefficients are dependent on these limits but also the functional forms are shaped by them.

\subsection{Performance Evaluations of GMPEs by Statistical Means}

It is commonly known that the aleatory (standard deviation, sigma) and the epistemic uncertainties have a strong influence on the seismic hazard analysis [30]. Generally, a logic-tree method is suggested to evaluate the uncertainties of various GMPEs selected by the methods explained in this study. The intention of this suggestion is based on the observed variability of the median ground motion estimations because of the associated sigma values. Therefore, in the evaluation of the performances of the functional forms of GMPEs, the median ground motions and the sigma values were considered separately.

Among the aforementioned statistical methods, together with the recently developed EDR method, the LLH method was used to measure the bias between the median estimations of ground motions and the observed values. The sigma values are also displayed in Table 2 in addition to the EDR and LLH values. The overall comparison of the results in Table 2 reveals that none of these values allow for the selection of a single equation. However, as it is recommended ([10, 29]), a number of equations could be selected to include in a logic-tree model. 
Karaca / Eskişehir Technical Univ. J. of Sci. and Tech. A-Appl. Sci. and Eng. 21 (1) - 2020

Table 2. The LLH, EDR and Sigma Values for PGA, T=0.2 s and $1.0 \mathrm{~s}$

\begin{tabular}{cccccccccc}
\hline \multirow{2}{*}{ GMPE } & \multicolumn{3}{c}{ PGA } & \multicolumn{3}{c}{$\mathrm{T}=0.2 \mathrm{~s}$} & \multicolumn{3}{c}{$\mathrm{T}=1.0 \mathrm{~s}$} \\
& LLH & EDR & $\sigma_{\ln (\mathrm{y})}{ }^{*}$ & LLH & EDR & $\sigma_{\ln (\mathrm{y})}$ & LLH & EDR & $\sigma_{\ln (\mathrm{y})}$ \\
\hline \hline KG04 & 1.76 & 0.90 & 0.61 & 1.85 & 1.04 & 0.75 & 1.92 & 1.14 & 0.85 \\
\hline AM05 & 1.76 & 0.92 & 0.63 & 1.88 & 1.09 & 0.81 & 2.04 & 1.30 & 1.02 \\
\hline AC10 & 1.74 & 0.87 & 0.58 & 1.85 & 1.05 & 0.76 & 1.97 & 1.23 & 0.93 \\
\hline AB10 & 1.75 & 0.90 & 0.62 & 1.87 & 1.08 & 0.80 & 2.00 & 1.26 & 0.98 \\
\hline ASK14 & 1.72 & 0.85 & 0.57 & 1.79 & 0.97 & 0.70 & 1.90 & 1.13 & 0.85 \\
\hline BSSA14 & $\mathbf{1 . 7 1}$ & $\mathbf{0 . 8 4}$ & $\mathbf{0 . 5 5}$ & $\mathbf{1 . 7 6}$ & $\mathbf{0 . 9 3}$ & $\mathbf{0 . 6 5}$ & $\mathbf{1 . 9 0}$ & $\mathbf{1 . 1 3}$ & $\mathbf{0 . 8 5}$ \\
\hline CB14 & 1.73 & 0.88 & 0.59 & 1.83 & 1.02 & 0.75 & 2.00 & 1.25 & 0.99 \\
\hline I14 & 1.75 & 0.89 & 0.60 & 1.82 & 1.00 & 0.72 & 1.93 & 1.17 & 0.88 \\
\hline * Standard
\end{tabular}

* Standard deviation of the GMPE or sigma

As indicated in bold, for PGA and spectral period of $0.2 \mathrm{~s}$, though the differences are very small with some of the GMPEs, the performance of BSSA14 can be singled out with the lowest LLH and EDR values associated with lower sigma values for almost the entire range of the spectrum.

Moreover, knowing the influence of the rupture and Joyner-Boore distance terms on the performance of GMPEs, the EDR values were computed for varying distance intervals as displayed in Figure 6. The distance intervals and the number of records falling under each interval are shown at the top of each subplot in the figure.

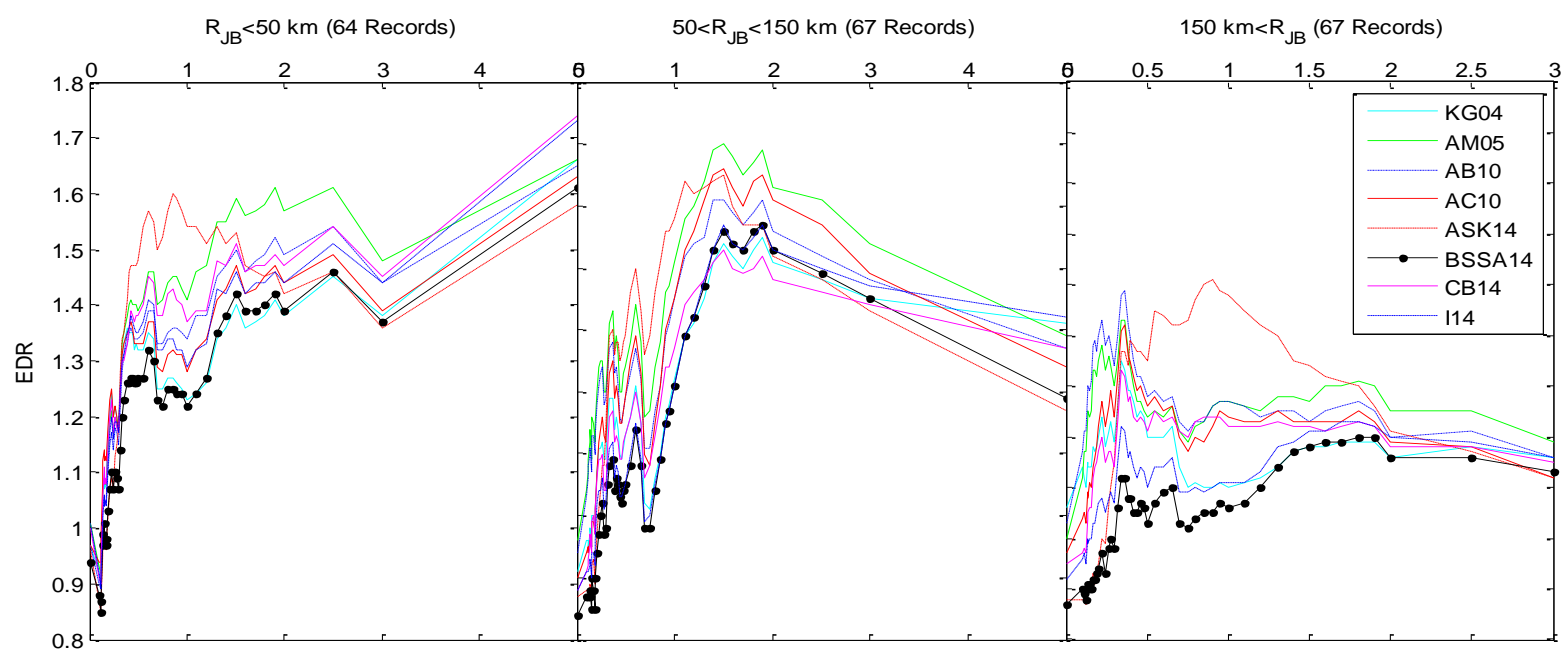

Period (s)

Figure 6.Variation of the EDR values for Different Distance Ranges

The distinctive performance of BSSA14, particularly for spectral periods up to $2.0 \mathrm{~s}$, should be noted for each distance interval. It should be indicated that the performance BSSA14 is more distinguishable for the highest distance range. Another important observation is that as the distance increases, the EDR values decrease for all the equations and periods. The same statistical test was applied in order to differentiate the performances of each equation with respect to different magnitude ranges (Figure 7). With respect to the magnitude increase, when compared with the results shown in Figure 6, almost the same pattern is observed in terms of the order of the equations and in the decline of EDR values for all the equations and for the entire period range. 
Karaca / Eskişehir Technical Univ. J. of Sci. and Tech. A - Appl. Sci. and Eng. 21 (1) - 2020

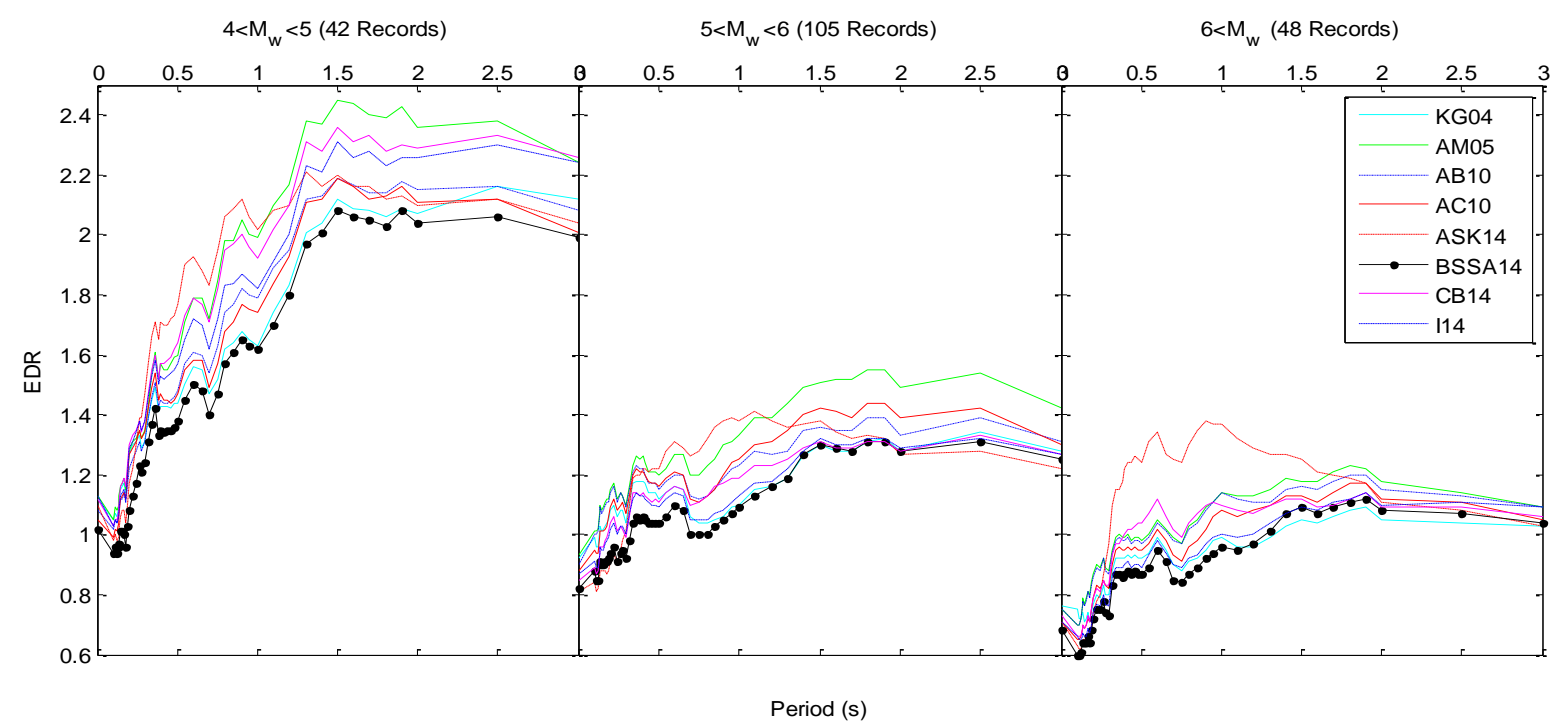

Figure 7.Variation of the EDR values for Different Magnitude Ranges

The variation of EDR values were further investigated for the ranges of average shear wave velocities of upper $30 \mathrm{~m}(\mathrm{Vs} 30)$. Similar to the procedure applied in generating distance and magnitude bins, the database was partitioned to three different bins. Considering Figures 6,7 and 8, it can be concluded that all the equations are performing well in the modeling of ground motions with large magnitude earthquakes at higher distances and for higher velocity ranges.

As it is clearly seen in Figure 8, BSSA14 outperforms the other models in all three ranges of velocities, and to the surprise of the author, the EDR values display a decreasing trend as velocity increases, similar to the distance and magnitude parameters. As a crucial indication of the level of competence of each functional form in the modeling of the local data, the sigma values offer crucial information. Since the database is limited in terms of the number of records and the existence of the high variation in the distribution of the records for each earthquake, sigma values were obtained using the fixed effect regression model, and the overall variance was computed for the entire spectral period range.

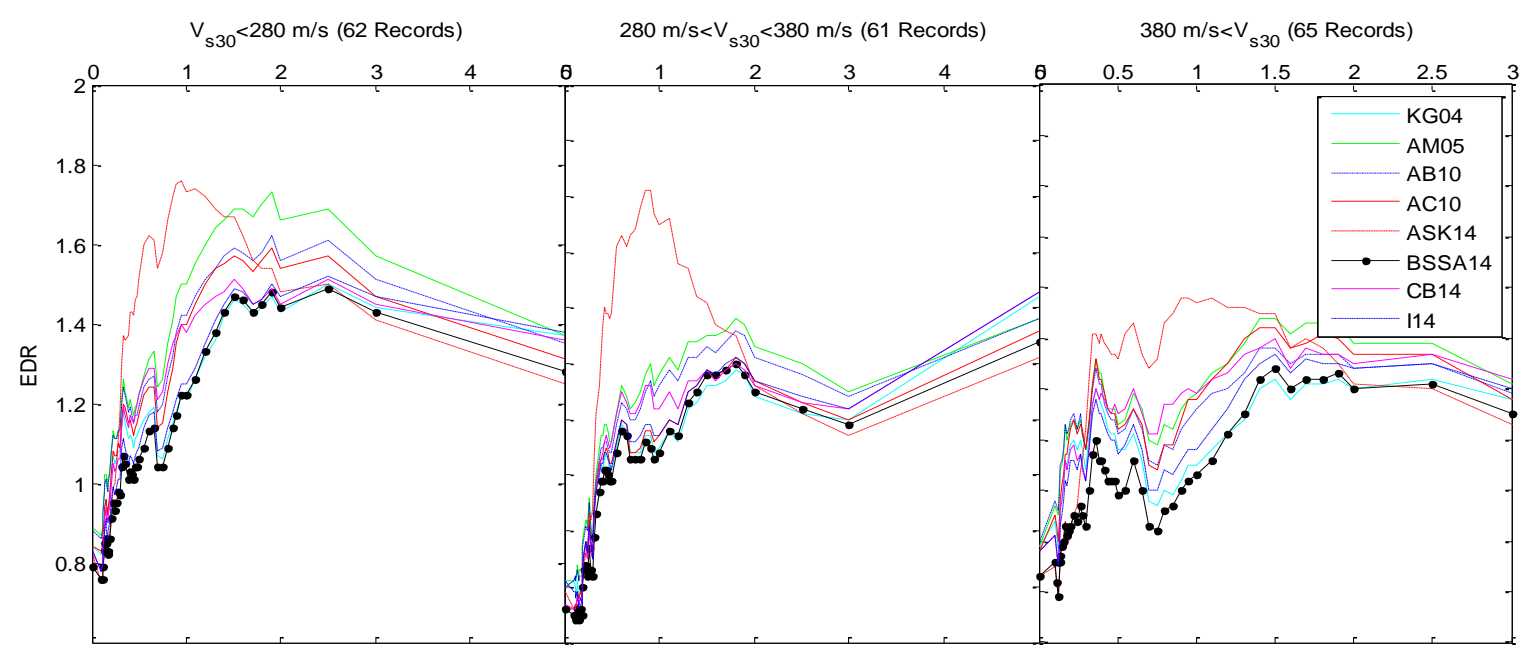

Period (s)

Figure 8.Variation of the EDR values for Different Velocity Ranges 
The order of equations with respect to the EDR values was confirmed in Figure 9, as the lowest sigma values are obtained for BSSA14. The associated values of the coefficient of determination are also provided in the right part of the figure. After the statistical tests, it can be said that the EDR and LLH tests and the observations of the sigma values are somehow adequate in the selection of the best performing functional form. In other words, the reduction of the number of candidate GMPEs from eight to one after a few statistical tests could be accepted as sufficient and a logic tree could be established to utilize the equations with the highest performances in a seismic hazard analysis.
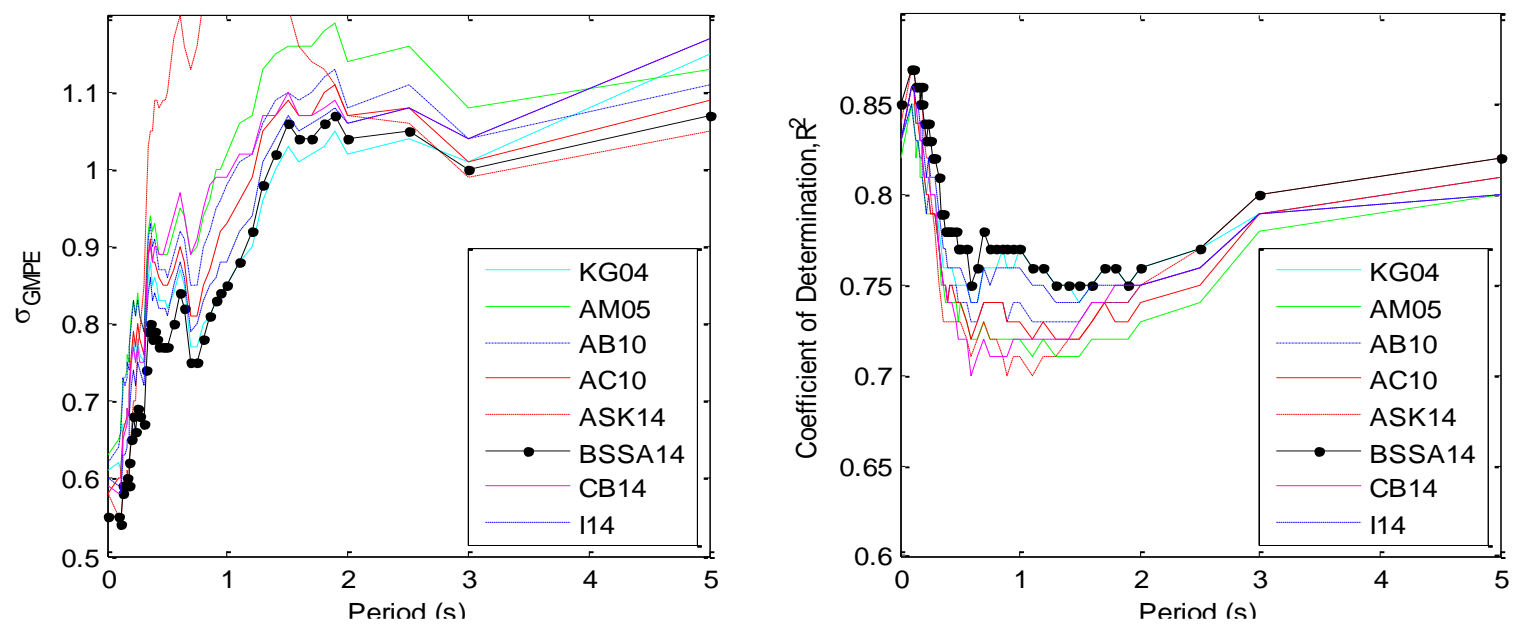

Figure 9. Variation of Sigma and Coefficient of Determination

However, in order to increase the level of precision and to confirm the obtained results, further investigation is needed. A classical residual analysis and testing the performance of the models with large magnitude earthquakes would provide the required confirmations of the statistical tests and would further provide information about the underlying reasons for success and failure of the tested functional forms.

\subsection{Residual Analysis}

Residual analysis was performed in order to ensure that there is not a modeling issue in the equations and to monitor the performances of the functional forms of the GMPEs with respect to the parameters of distance, magnitude and site class. The basic principle of the analysis is that if the residual can be expressed in terms of the fitted values, in other words, if there is a dependency of the residuals, then it becomes clear that there is a modeling issue in the function.

The variation of residuals with respect to distance was given special attention due to the reasons explained in Section 3.1. Model bias can be better measured by monitoring the most basic statistical measures of mean and standard deviation of the residuals for different ranges of the parameters, which is the distance in this case. Thus, the mean and standard deviation values were computed for each group and for each model, which are listed in Table 3 in a compact form.

The mean and standard deviation values display a mixed performance with respect to the distance range and the period. The values are generally the highest at $0.2 \mathrm{~s}$ and the distance range of $50-150 \mathrm{~km}$. Since the data is mostly populated by the 1999 İzmit and 1999 Düzce earthquakes for the distance above 150 $\mathrm{km}$, it can be concluded that the functional forms display a better performance with the records of these earthquakes. Among the evaluated functional forms, BSSA14 could be singled out as the lowest standard deviation values are observed for the entire range of distance and periods. 
Karaca / Eskişehir Technical Univ. J. of Sci. and Tech. A-Appl. Sci. and Eng. 21 (1)- 2020

Table 3. The Mean and Standard Deviation of the Residuals for Different Distance Bins at Selected Spectral Periods

\begin{tabular}{|c|c|c|c|c|c|c|c|c|c|c|c|c|}
\hline \multirow{2}{*}{ GMPE } & \multicolumn{6}{|c|}{ PGA* } & \multicolumn{6}{|c|}{$\mathrm{T}=0.2 \mathrm{~s}$} \\
\hline & $\mu_{0-50}$ & $\sigma_{0-50}$ & $\mu_{50-150}$ & $\sigma_{50-150}$ & $\mu_{150}$ & $\sigma_{150}$ & $\mu_{0-50}$ & $\sigma_{0-50}$ & $\mu_{50-150}$ & $\sigma_{50-150}$ & $\mu_{150}$ & $\sigma_{150}$ \\
\hline KG04 & -0.01 & 0.84 & 0.09 & 0.80 & -0.09 & 0.67 & -0.05 & 0.92 & 0.16 & 0.90 & -0.11 & 0.73 \\
\hline AM05 & -0.02 & 0.85 & 0.14 & 0.82 & -0.12 & 0.65 & -0.05 & 0.96 & 0.26 & 0.90 & -0.21 & 0.74 \\
\hline $\mathrm{AC} 10$ & -0.03 & 0.79 & 0.14 & 0.81 & -0.11 & 0.64 & -0.04 & 0.91 & 0.14 & 0.90 & -0.11 & 0.75 \\
\hline $\mathrm{AB} 10$ & -0.03 & 0.80 & 0.17 & 0.82 & -0.14 & 0.67 & -0.06 & 0.91 & 0.28 & 0.89 & -0.22 & 0.77 \\
\hline ASK14 & 0.01 & 0.80 & 0.07 & 0.80 & -0.07 & 0.61 & 0.00 & 0.87 & 0.08 & 0.85 & -0.09 & 0.65 \\
\hline BSSA14 & 0.01 & 0.79 & 0.07 & 0.78 & -0.08 & 0.61 & 0.04 & 0.89 & 0.05 & 0.81 & -0.09 & 0.66 \\
\hline CB14 & -0.02 & 0.82 & 0.10 & 0.81 & -0.09 & 0.63 & -0.04 & 0.92 & 0.15 & 0.90 & -0.11 & 0.70 \\
\hline I14 & 0.01 & 0.83 & 0.05 & 0.82 & -0.06 & 0.63 & 0.01 & 0.90 & 0.07 & 0.89 & -0.02 & 0.72 \\
\hline
\end{tabular}

* The mean and standard deviation values are the same for all distance ranges
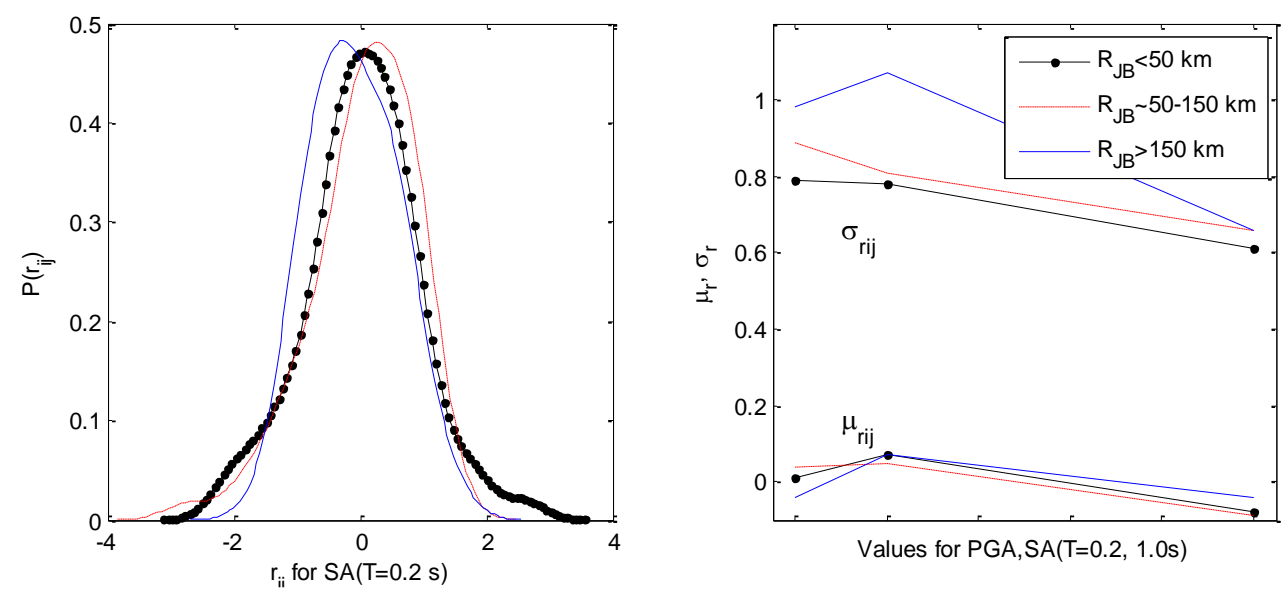

Figure 10. Variation of the Residuals for BSSA14 for Different Distance Ranges

For BSSA14, the distribution of residuals at each magnitude bin, and the mean and standard deviation values at PGA and spectral values of $0.2 \mathrm{~s}$ and $1.0 \mathrm{~s}$ are provided in Figure 10. The general trend found in all the models also repeats itself in BSSA14, as the mean and standard deviation values are higher at $0.2 \mathrm{~s}$. As the distance becomes larger, both values decrease, which is also a general trend for all the models.

Because of the information provided by the residual analysis, it can be said that none of the NGAWEST2 equations could be crossed out due to the poor performance, or otherwise could be selected for the best performance. As the statistical tests already pointed out BSSA14 as the best performer, further inquiry strengthen the results. Therefore, performance plots were generated by using the 1999 İzmit and 1999 Düzce earthquake data in order to compare the relative performances of the GMPEs. It should also be noted that as an extension to the residual analysis, the variation of the residuals with respect to magnitude and velocity could also be performed. However, as the locality of the distance scaling is strongly emphasized, only the residual variation with respect to distance is mentioned.

\subsection{Modeling of 1999 İzmit and 1999 Düzce Earthquake Ground Motions}

The precise modeling of the ground motions of large magnitude earthquakes is particularly important for the cases where a location might be subjected to the devastating effects of these earthquakes. Indeed, the knowledge about the local seismic propagation patterns becomes drastically important in the 
prediction of the influence of large magnitude earthquakes. Therefore, the capabilities of the functional forms in the modeling of 1999 İzmit and 1999 Düzce earthquakes were considered separately.

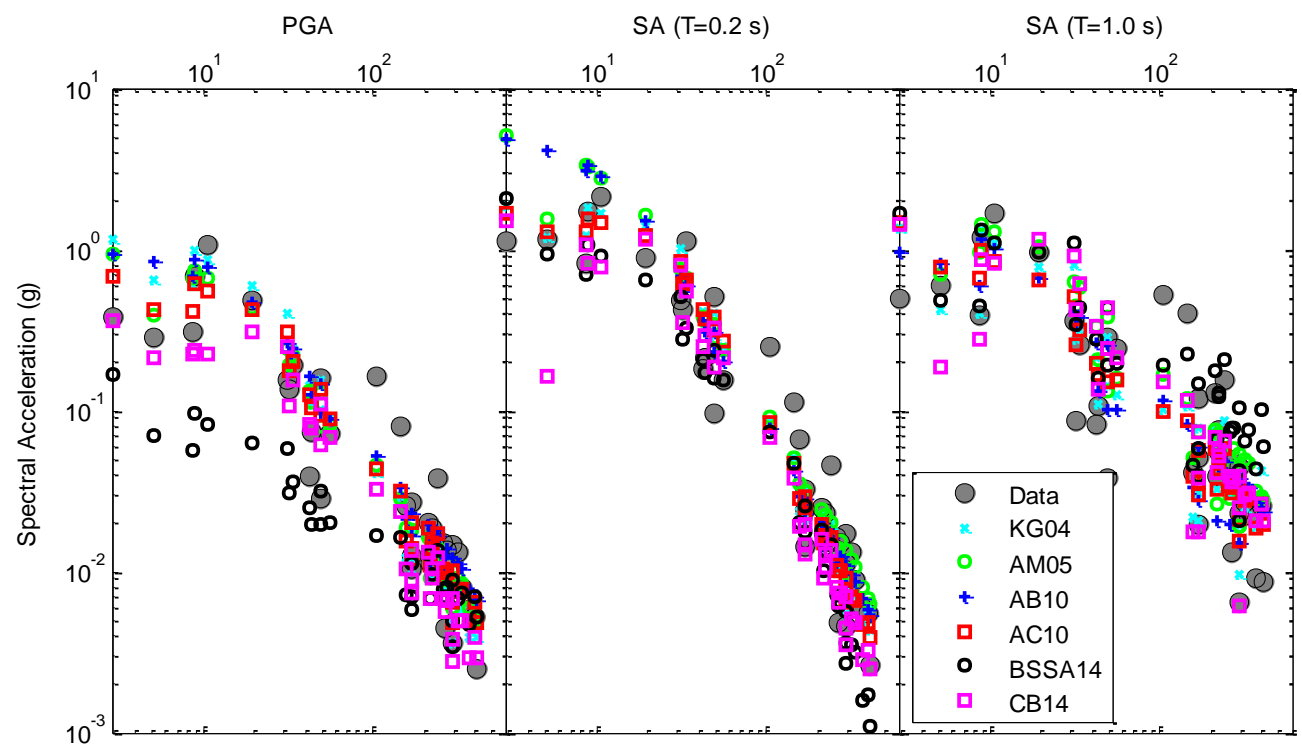

Joyner-Boore Distance $(\mathrm{km})$

Figure 11. Performance of Adopted GMPEs in Modeling the 1999 İzmit and 1999 Düzce Earthquake Data (ASK14 and I14 are not Shown Since the Computed Values are out of Range of the Displayed Values)

The devastating earthquakes of İzmit with a magnitude of 7.4 and Düzce with a magnitude of 7.2, yielded a number of valuable records, which indeed provide the opportunity to explore the ground motion propagation in the northwestern part of Anatolia. In the compiled database for this study, out of 198 records, 20 belong to İzmit earthquake and 16 belong to Düzce earthquake, respectively. The earthquakes were generated by the famous strike-slip fault of Northern Anatolian fault. The recording distance varies from $2.9 \mathrm{~km}$ to $409 \mathrm{~km}$ and the $\mathrm{V}_{\mathrm{s} 30}$ of the recording station sites ranges between 192 $\mathrm{km} / \mathrm{s}$ to $826 \mathrm{~km} / \mathrm{s}$. In order to predict the spectral acceleration values, all the parameters of magnitude, distance, site and fault parameters were employed. As shown in Figure 11, the predicted spectral acceleration values are generally in agreement with the measure acceleration values except for ASK14 and I14, which are not shown in the figure due to the high variation of spectral acceleration values. It should be reminded that both ASK14 and I14 use rupture distance as the distance parameter.

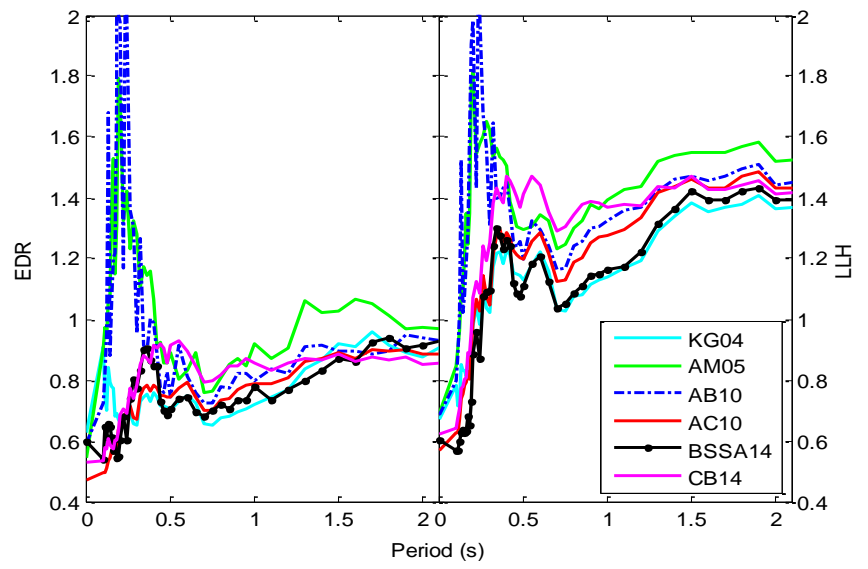

Figure 12.Results of EDR and LLH Analysis for KG04, AC10, AB10, BM14, ASK14, BSSA14, CB14 and I14 
The quantification of the correlation between the measured and predicted spectral acceleration values was performed by the EDR and LLH tests. Overall, BSSA14 can be singled out as the best performer in the modeling almost for the entire range of spectral periods as displayed in Figure 12. BSSA14 and KG04 were identified as the best performers among the models, whereas KG04 surpasses BSSA14 in the performance beyond $0.5 \mathrm{~s}$.
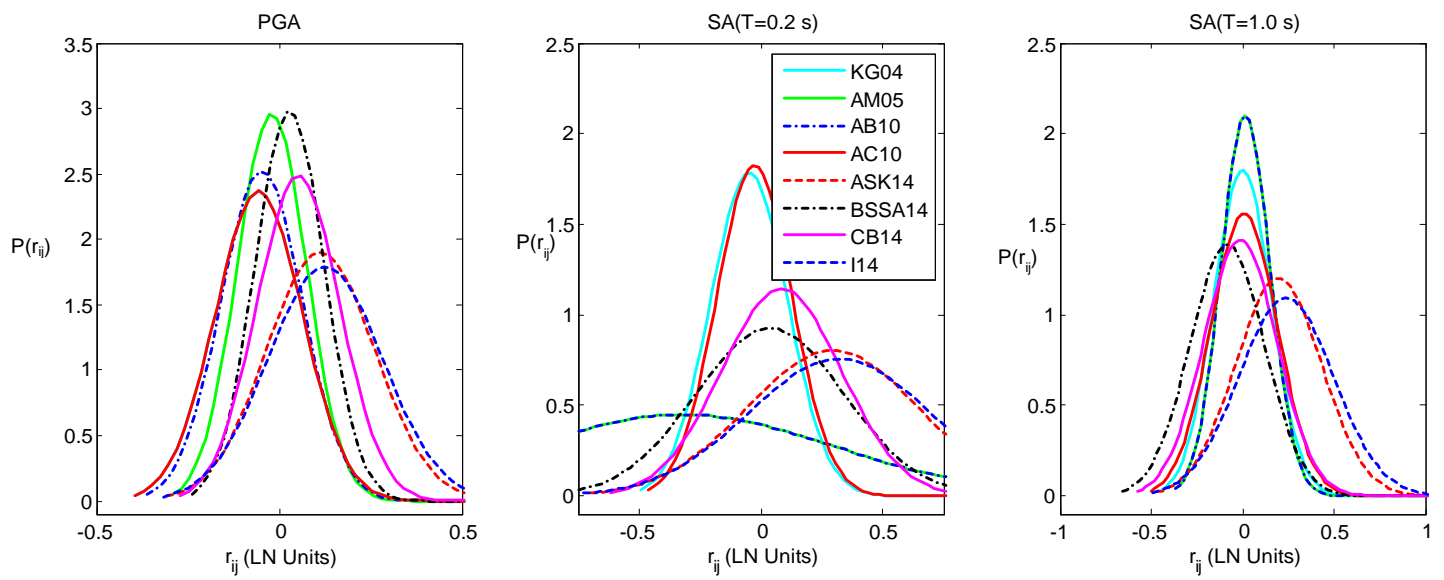

Figure 13. The Variation of the Residuals at PGA and SA (T=0.2 s, and $1.0 \mathrm{~s})$

Another significant observation is that the equations that use rupture distance, namely ASK14, I14 and CB14, fail to satisfactorily model the data when compared to the other equations, which constitutes a proof to the fact that the local data is best modeled by the Joyner-Boore distance. The residual mean and standard deviation values were computed for each spectral period. The variation of the residuals can be seen in Figure 13, which offers the relative sway of mean values of each model from zero and the relative spread from the mean. Surprisingly, no model can be singled out with its performance. The models display a mixed performance, which varies with spectral period. A closer look at Figure 13 gives clues about which models can be accepted as satisfactory in the modeling of İzmit and Düzce earthquakes. In addition, the sway of the mean values from zero, the spread of spectral acceleration at $T=0.2 \mathrm{~s}$, and the poor performance of some of the models are worth mentioning.

The models of AB10, AM05, ASK14 and I14 have a high spread of residuals with mean values above 0.50 (Table 4). Though the Turkish models of AC10 and KG04 have smaller values both for mean and standard deviation at certain spectral, if one has to choose among the models, BSSA14 could safely be identified as the best model with reasonable mean and standard deviations and statistical measures of the EDR and LLH values for the entire spectral period range.

\subsection{Final Selection}

Following all the assessments of the candidate GMPEs and particularly the performance plots, the determination of the right GMPE for the utilization in the local seismic hazard analysis is straightforward. Following the statistical tests, among the eight GMPEs listed in Table 4, BSSA14 was identified as the best performing equation.

Though residual analysis did not provide information that would finalize the results of the statistical tests, KG04, AC10 and AB10 were eliminated from the list due to the observed nonlinearity in the residual analysis. As a result, it should be mentioned that the success of BSSA14 in expressing the local seismic behavior is a convincing factor in the selection process. BSSA14, which was developed by using 
Joyner-Boore distance, is more reliable with the supporting statistical results obtained during the modeling of propagation of ground motions generated by İzmit and Düzce earthquakes. Considering the relatively successful performances, in the end, BSSA14 was selected as the most appropriate GMPE for seismic hazard analysis for Eskişehir.

Table 4. The Basic Statistical Measures for the Residuals

\begin{tabular}{ccccccc}
\hline GMPE & $\mu_{\text {PGA }}$ & $\sigma_{\text {PGA }}$ & $\mu_{\mathrm{t}=0.2}$ & $\sigma_{\mathrm{t}=0.2}$ & $\mu_{\mathrm{t}=1.0}$ & $\sigma_{\mathrm{t}=1.0}$ \\
\hline KG04 & -0.06 & 0.17 & -0.05 & 0.22 & 0.00 & 0.22 \\
\hline AM05 & -0.02 & 0.14 & -0.32 & 0.89 & 0.02 & 0.19 \\
\hline AB10 & -0.05 & 0.16 & -0.32 & 0.89 & 0.02 & 0.19 \\
\hline AC10 & -0.06 & 0.17 & -0.03 & 0.22 & 0.01 & 0.26 \\
\hline ASK14 & 0.11 & 0.21 & 0.29 & 0.50 & 0.20 & 0.33 \\
\hline BSSA14 & $\mathbf{0 . 1 0}$ & $\mathbf{0 . 2 0}$ & $\mathbf{0 . 0 9}$ & $\mathbf{0 . 3 2}$ & $\mathbf{- 0 . 0 7}$ & $\mathbf{0 . 2 6}$ \\
\hline CB14 & 0.05 & 0.16 & 0.08 & 0.35 & -0.01 & 0.29 \\
\hline I14 & 0.13 & 0.22 & 0.32 & 0.53 & 0.24 & 0.37 \\
\hline & & & & & &
\end{tabular}

\section{DISCUSSION}

The study is based on the idea that, before attempting to use, any selected GMPE should be adjusted and the coefficients must be calibrated before using it in a local seismic hazard analysis. A significant issue for adoption of a GMPE for local seismic hazard analysis is to determine whether there is a minimal number of local data for statistically meaningful adoption. The local database must be carefully selected in order to model the local biases and specific ground motion patterns. At the end of the study, the robust approach used in the evaluation of the parameters of the equations and the evaluation of the performances of functional forms of GMPEs yielded a conclusive result in the selection of the best performing equation. In addition, performance checks with the records of the two largest earthquakes clearly displayed the relative competency of various functional forms of the GMPEs in modeling the observed behavior.

Indeed, by looking at the results of this study, since the differences of performances of adopted GMPEs is close at certain ranges of periods, magnitudes, distances and velocities, one might easily come to conclusion that a logic-tree scheme might be more appropriate then choosing a single equation by just relying on statistical data. However, the introduction of several testing procedures and testing with the large earthquake data offered a more robust approach in choosing the best performing equation without leaving much doubts. Each method used in this study, including the statistical procedures of EDR and LLH and the residual analysis, provides a different aspect of the performance levels of each functional form of GMPEs with the local data.. Hence, the variation of the performances of equations with respect to the various methods is the source of robustness of the evaluation. Furthermore, if the local propagation is specifically biased not because of the lack of records but because of the nature of the area, then this distinctiveness has to be identified before deciding on the right functional form of a GMPE. The data of two large earthquakes just provided such information with a considerable number of records are available for each event.

Last but not the least, it should be mentioned that, as the number of parameters increase and the GMPE becomes more complex, it becomes much more difficult to adjust a GMPE to suit another location. Fewer parameters and less complexity in a GMPE increase the chances of adoption through adjustments to local conditions, which otherwise would remain specific to the used database in development stage. More simpler forms should be preferred if a functional form is sought to fit the local data. As a result, it 
can be concluded that equations with fewer complex parameters and split magnitude values have more chance to be valid for general use.

\section{REFERENCES}

[1] Campbell KW.. Prediction of Strong Ground Motion Using the Hybrid Empirical Method and Its Use in the Development of Ground-Motion (Attenuation) Relations in Eastern North America. Bull SeismolSoc Am2003; 93:1012-1033.

[2] Douglas J An investigation of analysis of variance as a tool for exploring regional differences in strong ground Motions. J Seismol 2004; 8:485-486

[3] Douglas J. On the regional dependence of earthquake response spectra. ISETJ EarthqTechnol 2007; 44:71-99.

[4] Hintersberger E, Scherbaum F, Hainzl S. Update of likelihood-based ground-motion model selection for seismic hazard analysis in Western Central Europe. Bull Earthquake Eng 2007;5:1-16.

[5] Stafford PJ, Strasser FO, Bommer JJ. An evaluation of the applicability of the NGA models to ground motion prediction in the Euro-Mediterranean Region. Bull Earthquake Eng 2008; 6:149-177.

[6] Stewart JP, Scasserra G, Lanzo G, Mollaioli F, Bazzurro P. Critical evaluation of Italian strong motion data and comparison to NGA ground motion prediction equations, Report No. UCLA SGEL 2008/03, University of California, Los Angeles, 2008

[7] Scassera G, Stewart JP, Bazzurro P, Lanzo G, Mollaioli F. A comparison of NGA ground motion prediction equations to Italian data. Bull Seismol Soc Am 2009; 99:2961-298.

[8] Bommer JJ, Douglas J, Scherbaum F. et al. On the Selection of Ground Motion Prediction Equations for Seismic Hazard Analysis. Seismol Res Lett 2010; 81:783-793.

[9] Delavaud E, Scherbaum F, Kuehn N. Testing the global applicability of groundmotion prediction equations for active shallow crustal regions. Bull SeismolSoc Am 2012; 102:707-721.

[10] Douglas J, Akkar S, Ameri G, Bard PY, Bindi D et al. Comparisons among the five ground-motion models developed using RESORCE for the prediction of response spectral accelerations due to earthquakes in Europe and the Middle East. Bull Earthquake Eng 2014; 12:341-358.

[11] Gülerce Z, Kargıglu B., Abrahamson N.A. Turkey-Adjusted NGA-W1 Horizontal Ground Motion Prediction Models. Earth Spectra 2015; 32:75-100.

[12] Ancheta TD, Darragh RB, Stewart JP et al (2013). PEER NGA-West2 Database, PEER Report No. 2013/03, Pacific Earthquake Engineering Research Center, University of California, Berkeley, CA, 2013; 134 pp.

[13] Bindi D, Massa M, Luzi L, Ameri G, Pacor F, Puglia R, Augliera P. Pan-European ground-motion prediction equations for the average horizontal component of PGA, PGV, and 5\%-damped PSA at spectral periods up to $3.0 \mathrm{~s}$ using the RESORCE dataset. Bull Earthquake Eng 2014a,b; 12:391430.

[14] http://kyhdata.deprem.gov.tr Last Access Date: January, 2019 
[15] Akkar S., Sandıkkaya M.A., Şenyurt M., Azari Sisi A., Ay B.Ö., Traversa P., Douglas J., Cotton F.,Luzi L., Hernandez B., Godey S. Reference database for seismic ground-motion in Europe (RESORCE), Bull Earthquake Eng 2014;12(1);311-339

[16] Akkar S, Cağnan Z, Yenier E, Erdoğan E, Sandikkaya MA, Gülkan P. The recently compiled Turkish strong-motion database: preliminary investigation for seismological parameters. J Seismol 2010; 14: 457-479.

[17] Abrahamson NA, Silva WJ, Kamai R. Summary of the Abrahamson, Silva, and Kamai NGA-West2 ground-motion relations for active crustal regions. Earthq Spectra; 2014 30:1025-1056.

[18] Boore DM, Stewart J, Seyhan E, Atkinson G. NGA-West2 equations for predicting response spectral accelerations for shallow crustal earthquakes. Earthq Spectra 2014; 30:1057-1086.

[19] Campbell KW, Bozorgnia Y. Campbell-Bozorgnia NGA-West2 ground motion model for the average horizontal components of PGA, PGV, and 5\%-damped linear response spectra. Earthq Spectra 2014; 30:1087-1116.

[20] Chiou BSJ, Youngs R. Update of the Chiou and Youngs NGA ground motion model for average horizontal component of peak ground motion and response spectra. Earthq Spectra 2014; 30:111754

[21] Idriss I. An NGA-West2 empirical model for estimating the horizontal spectral values generated by shallow crustal earthquakes. Earthq Spectra 2014; 30:1155-1178.

[22] Ambraseys NN, Douglas J, Sarma SK, Smit P. Equations For The Estimation Of Strong Ground Motions From Shallow Crustal Earthquakes Using Data From Europe And The Middle East: Horizontal Peak Ground Acceleration And Spectral Acceleration. Bull Earthquake Eng 2005; Vol. $3,1-53$.

[23] Akkar S, Bommer JJ. Empirical Equations for the Prediction of PGA, PGV, and Spectral Accelerations in Europe, the Mediterranean Region, and the Middle East. Seismol Res Lett 2010; 81:195-206.

[24] Kalkan E. and G"ulkan P. Site-Dependent Spectra Derived From Ground Motion Records İn Turkey; Earthquake Spectra 2004; 20(4) 1111-1138

[25] Akkar S, Cağnan Z. A local ground motion predictive model for Turkey and its comparison with other regional and global ground-motion models. Bull Seismol Soc Am 2010; 100:2978-2995

[26] Akkar S, Sandıkkaya MA, Bommer JJ. Empirical ground-motion models for point- and extendedsource crustal earthquake scenarios in Europe and the Middle East. Bull Earthquake Eng 2013; 12: 359-387.

[27] Cotton F, Scherbaum F, Bommer JJ, Bungum H. Criteria for selecting and adjusting ground-motion models for specific target regions: Application to Central Europe and rock sites. J Seismol 2006; 10:137-156.

[28] Scherbaum F, Delavaud E, Riggelsen C. Model Selection in Seismic Hazard Analysis: An Information-theoretic Perspective. Bull Seismol Soc Am 2009; 99:3234-3247. 
Karaca / Eskişehir Technical Univ. J. of Sci. and Tech. A-Appl. Sci. and Eng. 21 (1)-2020

[29] Kale Ö, Akkar S. A new procedure for selecting and ranking ground-motion prediction equations (GMPEs): the euclidean-distance based ranking (EDR) method, Bull Seismol Soc Am. 2013; 103:1069 - 1084.

[30] Bommer JJ, Abrahamson NA. The Variability of Ground-Motion Prediction Models and Its Components. Bull Earthquake Eng 2006; 96:1967-1977. 